\title{
Occurrence of adenovirus infection and clinical impact in paediatric stem cell transplant recipients
}

\author{
Gabriele Bianco, ${ }^{1}$ Cristina Costa, ${ }^{1}$ Andrea Piceghello, ${ }^{1}$ Francesca Sidoti, ${ }^{1}$ Mareva Giacchino, ${ }^{2}$ \\ Rossana Cavallo ${ }^{1}$ \\ ${ }^{1}$ Microbiology and Virology Unit; ${ }^{2}$ Oncohematology Unit, University Hospital "Città della Salute e \\ della Scienza", Turin, Italy
}

\section{Summary}

In this study, the occurrence and clinical impact of adenovirus (AdV) infection was investigated in paediatric hematopoietic stem cell transplantation (HSCT) recipients. A number of 603 specimens (including whole blood, respiratory and other samples) from 181 patients were tested by real-time polymerase chain reaction; clinical outcome was investigated. Overall, 118/603 (19.6\%) specimens from 21/181 (11.6\%) patients resulted positive to AdV (including 17.3, 29.9, 17.6, and 15.8\% of total number of whole blood, respiratory, urine and other specimens, respectively). On whole blood specimens, viral loads ranged from $<600$ (limit of detection) to $>5 \times 10^{6}$ copies $/ \mathrm{mL}$, with a median value $2 \times 10^{4}$. Multiple specimens were positive in patients in which viral load on whole blood was high. Adenoviral positivity on whole blood was associated to poor prognosis, as death occurred in three of ten (30\%) patients with persistent positivity on whole blood specimens, also despite the administration of an antiviral agent (cidofovir).

Correspondence: Cristina Costa, Microbiology and Virology Unit, University Hospital Città della Salute e della Scienza di Torino, Corso Bramante 88, 10126 Turin, Italy.

Tel.: +39.011.6335953. Fax: +39.011.6335194.

E-mail: cristina.costa@unito.it

Key words: Adenovirus; Haemopoietic stem cell transplantation; Paediatric patients.

Contributions: GB, AP, FS, specimen collection and processing, data analysis; $\mathrm{CC}$, study coordination, manuscript preparation; MG, collection of clinical data, data analysis; RC, study coordination and supervision.

Conflict of interest: the authors declare no potential conflict of interest.

Received for publication: 26 February 2016.

Revision received: 14 April 2016.

Accepted for publication: 18 April 2016.

(C) Copyright G. Bianco et al., 2016

Licensee PAGEPress, Italy

Microbiologia Medica 2016; 31:5850

doi:10.4081/mm.2016.5850

This article is distributed under the terms of the Creative Commons Attribution Noncommercial License (by-nc 4.0) which permits any noncommercial use, distribution, and reproduction in any medium, provided the original author(s) and source are credited.
Adenovirus infection can account for systemic and/or organ-specific signs/symptoms in approximately $10 \%$ of paediatric HSCT recipients. At moment, there is no indication for routine monitor of AdV in these patients, although AdV aetiology of infectious transplant complications should be taken in account.

\section{Introduction}

Hematopoietic stem cell transplantation (HSCT) represents the last treatment for a variety of diseases, including lymph proliferative disorders, leukaemia, and bone marrow failure syndromes. However, transplant-related mortality remains the main limitation to its success. In addition to the development of graft-versus-host disease (GVHD), infections are important complications during HSCT procedures and contribute significantly to morbidity and transplantation-related mortality. The periods at highest risk of infections occur during the immunosuppressed phase and in the period preceding the immune reconstitution. The risk of infection is higher for allogeneic HSCT, GVHD, delayed immune reconstitution and the incidence and severity of infections strongly correlate with pretransplantation serostatus, source of HSC, time elapsed for HSCT, unrelated of human leukocyte antigen-mismatched related donor transplantation, immunosuppressive therapy, use of total body irradiation, fludarabine, antilymphocyte serum and monoclonal antibodies during the conditioning regimen $(8,13)$.

Viral infections/reactivations represent one of the main infectious risk in $\operatorname{HSCT}(7,10,12)$. The viral agents mainly involved are cytomegalovirus, Epstein-Barr virus, adenovirus (AdV), varicella zoster virus and herpes simplex virus. In the last years, there has been an increase in the number of viral diseases observed in these patients. This may be at least partially due to an improvement in diagnostic facilities, but the increasing number of transplants procedures and the more severe immunosuppression may also have played an important role. Recently, AdV has been increasingly recognised with emerging significance after transplantation, with a particularly aggressive course of viral disease (e.g. severe respiratory disease, hepatitis, colitis, haemorrhagic cystitis, and keratoconjunctivitis), and a higher mortality rate $(8-26 \%)$. The frequency of $\mathrm{AdV}$ infections in paediatric transplant recipients is significantly higher than in adults. About 2-5 fold higher infection rates have been reported (1-6,10-14). Young paediatric transplant recipients seem to be at especially high risk, possibly because of a higher rate of primary infection as compared to reactivation in adolescent patients or adults. Patient selection for antiviral therapy, choice of drug, optimal timing of therapy and monitoring of therapeutic effects, treatment of AdV infections remain a domain of controversy. A recent article by Minarek and colleagues (9) found that despite a low mortality directly attributed to AdV infection, blood AdV loads $>10,000$ copies/mL were significant and independent risk factors 
for poor survival and recommended AdV blood monitoring for at least 50 days for paediatric HSCT with early occurrence of DNA positivity in blood predisposing for development of high viral loads.

\section{Materials and Methods}

In this study, the occurrence and clinical impact of AdV infection was investigated in a population of paediatric HSCT recipients.

Of patients 181 (106 males/75 females; mean age, 8.4 \pm 5.6 years; range, 5-19) who underwent HSCT were evaluated for AdV infection at the Microbiology and Virology Unit of the University Hospital Città della Salute e della Scienza di Torino (Turin, Italy).

AdV was not tested routinely, but in the presence of clinical and/or laboratory and/or radiological signs and/or symptoms suggestive of $\mathrm{AdV}$ infection (i.e. systemic symptoms, including fever, and organ-specific symptoms indicative of respiratory, keratoconjuntival, gastrointestinal, urinary, central nervous system involvement) or for checking-up a previous positivity (in this case usually at weekly until negativity).

Overall, 603 specimens collected on clinical indication (including occurrence of systemic or organ disease) were evaluated: in particular, 472 whole blood specimens from 114 patients; 87 respiratory specimens (nasopharyngeal swabs, bronchoaspirate, bronchoalveolar lavage) from 66 patients; 17 urine samples from nine patients; 8 keratoconjuntival swabs from two patients; and 19 other specimens (including cerebrospinal fluid, bone marrow, pleuric and peritonitic fluid, tissue biopsy). Multiple and different specimens were available for 56 patients (mainly whole blood and one or more other samples).

All the specimens were tested by a commercially available real-time polymerase chain reaction (PCR) assay (Adenovirus ELIte MGB® kit; ELITech Italy, Trezzano s.N., Italy) following automated extraction by the Qiasymphony instrument (Qiagen, Hilden, Germany) Amplification was performed with the 7500 real-time PCR systems (Applied Biosystems, Foster City, CA, USA).

\section{Results}

Overall, 118/603 (19.6\%) specimens from 21/181 (11.6\%) patients resulted positive to AdV. In particular, considering the different speci- mens, 82/472 (17.3\%) whole blood specimens from 10/114 (8.7\%) patients for which this specimen was tested; $26 / 87$ (29.9\%) respiratory samples from 11/66 (16.7\%) patients; three of 17 (17.6\%) urine specimens from 2/9 (22.2\%) patients; and three of 19 (15.8\%) other specimens from two patients. No keratoconjuntival sample was positive. On whole blood specimens, viral loads ranged from $<600$ (limit of detection) to $>5 \times 10^{6}$ copies $/ \mathrm{mL}$, with a median value $2 \times 10^{4}$; in particular, this was $<600$ copies/mL in 14/82 (17.1\%) specimens, between 600 and 10,000 copies/mL in 12 (14.6\%), and >10,000 copies/mL in the remaining samples. Peak viral loads were $<600$ in $2 / 10(20 \%)$ patients, between 600 and 10,000 in two (20\%), and >10,000 in six (60\%). Multiple specimens were positive in patients in which viral load on whole blood was high. Adenoviral positivity on whole blood was associated to poor prognosis, as death occurred in three of ten (30\%) patients with persistent positivity on whole blood specimens, in the absence of other infections or progression of underlying disease. In two of these patients (a 16 year-old girl and a 9-year-old boy) viral load values $>10^{4}$ copies/mL whole blood persisted for 3 and 6 months, respectively (until death), despite the administration of an antiviral agent (cidofovir), suggesting that both high viral load and persistent positivity could be suggestive of poor prognosis. Patients' features in relation to viral load in whole blood specimens are reported in Table 1.

\section{Conclusions}

Adenovirus has been increasingly recognized as possibly playing a relevant role in clinical outcome of HSCT paediatric patients. Based on the results of this study, AdV infection can account for systemic and/or organ-specific signs/symptoms in approximately $10 \%$ of paediatric HSCT recipients. A wide range of occurrence rates of organ or systemic AdV infection in HSCT patients has been reported in previous studies (1-7,10-14). Risk factors associated to AdV infection in HSCT include Tcell depletion, unrelated and cord blood HSCT, GVHD, and lymphopenia. Based on our and other studies, AdV infections appears to play a relevant role in terms of patient outcome, particularly in the presence of disseminated infection, that usually follows a primary local infection. AdV positivity can be detected in different clinical specimens, with high and persisting viral load on whole blood specimens. In a previous study (9), early detection of AdV in blood before day 50 post transplantation

Table 1. Patients' features in relation to adenovirus systemic infection. Viral load is on whole blood specimens.

\begin{tabular}{|c|c|c|c|c|c|}
\hline & Negative & $\begin{array}{r}\text { Peak } \\
<600 \text { copies/mL }\end{array}$ & $\begin{array}{l}\text { enovirus load } \\
600-10,000 \text { copies/mL }\end{array}$ & $>10,000$ copies/mL & $\mathbf{P}$ \\
\hline $\begin{array}{l}\text { Sex } \\
\text { Male } \\
\text { Female }\end{array}$ & $\begin{array}{l}67 \\
37\end{array}$ & $\begin{array}{l}1 \\
0\end{array}$ & $\begin{array}{l}1 \\
1\end{array}$ & $\begin{array}{l}6 \\
1\end{array}$ & 0.56 \\
\hline $\begin{array}{l}\text { Age } \\
<6 \text { years } \\
>6 \text { years }\end{array}$ & $\begin{array}{l}58 \\
46\end{array}$ & $\begin{array}{l}0 \\
1\end{array}$ & $\begin{array}{l}0 \\
2\end{array}$ & $\begin{array}{l}3 \\
4\end{array}$ & 0.26 \\
\hline $\begin{array}{l}\text { Underlying disease } \\
\text { Acute/chronic leukaemia } \\
\text { Lymphoma } \\
\text { Congenital diseases } \\
\text { Others }\end{array}$ & $\begin{array}{c}95 \\
2 \\
1 \\
6\end{array}$ & $\begin{array}{l}1 \\
0 \\
0 \\
0\end{array}$ & $\begin{array}{l}2 \\
0 \\
0 \\
0\end{array}$ & $\begin{array}{l}7 \\
0 \\
0 \\
0\end{array}$ & 1 \\
\hline $\begin{array}{l}\text { Conditioning regimens } \\
\text { Treosulfan-based } \\
\text { Busulfan-based } \\
\text { TBI-based } \\
\text { Others }\end{array}$ & $\begin{array}{l}24 \\
24 \\
46 \\
10\end{array}$ & $\begin{array}{l}0 \\
0 \\
1 \\
0\end{array}$ & $\begin{array}{l}1 \\
0 \\
1 \\
0\end{array}$ & $\begin{array}{l}2 \\
2 \\
2 \\
1\end{array}$ & 0.95 \\
\hline
\end{tabular}


was a major independent risk factor for the development of high viral loads (>10,000 copies/mL). In these patients, pre-emptive cidofovir treatment correlated with low AdV-attributed mortality. At moment, there is no indication for routine monitoring of AdV in paediatric HSCT recipients; however, AdV aetiology of infectious transplant complications should be taken in account. Further studies are necessary to identify type, dosage and timing of antiviral treatment, and the potential role for AdV-specific T-cell therapy (8).

\section{References}

1. Anderson EJ, Guzman-Cottrill JA, Kletzel M, et al. High-risk adenovirus-infected pediatric allogeneic hematopoietic progenitor cell transplant recipients and preemptive cidofovir therapy. Pediatr Transplantation 2008;12:219-27.

2. Bil-Lula I, Ussowicz M, Rybka B, et al. PCR diagnostics and monitoring of adenoviral infections in hematopoietic stem cell transplantation recipients. Arch Virol 2010;155:2007-15.

3. Erard V, Huamg M-L, Ferrenberg J, et al. Quantitative real-time polymerase chain reaction for detection of adenovirus after $\mathrm{T}$ cellreplete hematopoietic cell transplantation: viral load as a marker for invasive disease. CID 2007;45:958-65.

4. George D, El-Mallawany NK, Jin Z, et al. Adenovirus infection in paediatric allogeneic stem cell transplantation recipients is a major independent factor for significantly increasing the risk of treatemtn related mortality. Br J Haematol 2011;156:99-108.

5. Gustafson I, Lindblom A, Yun Z, et al. Quantification of adenovirus DNA in unrelated donor hematopoietic stem cell transplant recipients. J Clin Virol 2008;43:79-85.

6. Lee YJ, Chung D, Xiao K, et al. Adenovirus viremia and disease: comparison of $\mathrm{T}$ cell-depleted and conventional hematopoietic stem cell transplantation recipients from a single institution. Biol Blood Marrow Transplant 2013;19:387-92.

7. Lo MS, Lee GM, Gunawardane N, et al. The impact of RSV, adenovirus, influenza, and parainfluenza infection in pediatric patients receiving stem cell transplant, solid organ transplant, or cancer chemotherapy. Pediatr Transplantation 2013;17:133-43.

8. Matthes-Martin S, Feuchtinger T, Shaw PJ, et al. European guidelines for diagnosis and treatment of adenovirus infection in leukemia and stem cell transplantation: summary of ECIL-4 (2011). Transplant Infect Dis 2012;14:555-63.

9. Mynarek M, Ganzenmueller T, Mueller-Heine A, et al. Patient, virus, and treatment-related risk factors in pediatric adenovirus infection after stem cell transplantation: results of a routine monitoring program. Biol Blood Marrow Transplant 2014;20:250-6.

10. Schönberger S, Meisel R, Adams 0, et al. Prospective, comprehensive, and effective viral monitoring in children undergoing allogeneic hematopoietic stem cell transplantation. Biol Blood Marrow Transplant 2010;16:1428-35.

11. Symeonidis N, Jakubowski A, Pierre-Louis S, et al. Invasive adenoviral infections in T-cell depleted allogeneic hematopoietic stem cell transplantation: high mortality in the era of cidofovir. Transplant Infect Dis 2007;9:108-13.

12. Verdeguer A, de Heredia CD, Gonzalez M, et al. Observational prospective study of viral infections in children undergoing allogeneic hematopoietic cell transplantation: a 3-year GETMON experience. Bone Marrow Transplant 2011;46:119-24.

13. Watson T, MacDonald D, Song X, et al. Risk factors for molecular detection of adenovirus in pediatric hematopoietic stem cell transplantation recipients. Biol Blood Marrow Transplant 2012;18:1227-34.

14. Zheng X, Lu X, Erdman DD, et al. Identification of adenoviruses in specimens from high-risk pediatric stem cell transplant recipients and controls. J Clin Microbiol 2008;46:317-20. 